\title{
Eu vim para que todos tenham vida
}

\author{
Paulo Cezar Costa
}

\section{Em Cristo, Deus se decidiu pelo ser humano}

A reflexão bíblica do Novo Testamento, principalmente, Paulo e João, situa o primado de Cristo no plano da criação e da salvação. Em 1Cor 8, 5-6, Paulo diz: “...existe um só Deus, o Pai de quem tudo procede (exhou ta panta) e para quem nós somos e um só Senhor, Jesus Cristo, por quem tudo existe (di hou tà pánta) e por quem nós somos...". O Filho é apresentado aqui como mediador da criação. O ser e o ser salvo não podem proceder de dois princípios distintos, mas de um único. Este papel de mediador não é realizado autonomamente por Cristo, mas na dependência daquele de quem tudo procede ${ }^{1}$. Também no hino da epístola aos Colossenses (Col 1, 15-18) Cristo é apresentado como primogênito de toda a criação, porque Nele tudo foi criado e como causa da criação: tudo foi criado por Ele e para Ele. Franz Mussner comenta: “...o mundo foi criado 'para ele', enquanto Cristo é a meta escondida e graciosa da criação e sua dinâmica, a causa finalissobrenatural de todo ser" ${ }^{\text {. }}$. Também o prólogo de João proclama a função mediadora do Logos na criação: Tudo foi feito por meio dele e sem ele nada foi feito (Jo 1, 3). O mesmo Logos, mediador da criação, é aquele que trás luz e vida. Criação e redenção nesta perspectiva não se separam. Assim, nos

\footnotetext{
${ }_{1}^{1}$ J. L. Ruiz de la PeÑa, Teologia da Criação, Edições loyola, São Paulo, 1989, p. 58-59.

${ }^{2}$ F. Mussner, "Criação em Cristo", in Mysterium Salutis, II/2, Editora Vozes, Petrópolis, 1972, p. 53.
} 
hinos pré-paulinos e no prólogo joaneu criação e salvação estão estreitamente ordena"das uma para a outra e isto, em Cristo, mediador da criação, que simultaneamente é aquele "para quem" o universo foi criado.

Se o Novo Testamento refletiu sobre este direcionamento intrínseco da criação para a salvação em Cristo, também a reflexão patrística e a teologia atual vêem esta ligação fundamental entre Cristologia e antropologia. Santo Irineu, no segundo século, dizia que na encarnação do Verbo nós visualizamos aquele do qual fomos criado imagem. K. Rahner diz que após a Encarnação, a antropologia sempre se há de considerar como cristologia deficiente e a cristologia como fim e fundamento da antropologia, porque em Jesus se revelou historicamente e se encontra de modo inexcedivel o que e quem é o homem. Em vista disso, é evidente que uma protologia adequada não é possivel senão sob o aspecto escatológico, isto é, a partir de Cristo ${ }^{3}$. Há uma relação profunda e intrínseca entre Cristologia e antropologia, pois o mistério do ser humano encontra a sua realização plena e definitiva no mistério do Verbo Encarnado.

\section{A Encarnação do Verbo, caminho de vida e de realização do humano}

Se a criação está intrinsecamente orientada para a Encarnação, na Encarnação do Verbo, o ser humano visualizou o seu caminho. A Constituição Pastoral Gaudium et Spes no n. 22 afirma que o mistério do homem encontra o seu sentido no mistério do Verbo Encarnado: Na realidade o mistério do homem só se torna claro verdadeiramente no mistério do Verbo Encarnado. Com efeito, Adão o primeiro homem era figura daquele que devia vir, isto é, de Cristo Senhor. Novo Adão, na mesma revelação do mistério do Pai e do seu amor, Cristo manifesta plenamente o homem ao próprio homem e lhe descobre a sua altíssima vocação. Neste plano de realização, o ministério terreno de Jesus, sua vida, morte e ressurreição se tornam assim, paradigmático para o ser humano.

O Centro do ministério de Jesus foi anúncio do Reino de Deus. Neste anúncio, Jesus manifesta que a sua salvação atinge a pessoa humana na sua integralidade, manifesta que o Deus de Jesus Cristo é o Deus da vida. Esta opção pela vida na sua integralidade, Jesus a expressa na sinagoga de Nazaré, quando lendo o profeta Isaías, Ele proclama: O Espírito do Senhor está sobre mim, porque ele me ungiu para Evangelizar os pobres; enviou-me para proclamar a remissão aos presos e aos cegos a recuperação da vista,

\footnotetext{
${ }^{3}$ K. RAHNER, "Reflexões fundamentais sobre a antropologia e a protologia no conjunto da Teologia”, in Mysterium Salutis, II/2, Editora Vozes, Petrópolis, 1972, p. 17.
} 
para restituir a liberdade aos oprimidos e para proclamar um ano de graça do Senhor [...]. Então começou a dizer: hoje se cumpriu aos vossos olhos essa passagem da Escritura (Lc 4, 18-21).

A menção de categorias muito concretas: pobres, presos, cegos, oprimidos, devia soar provocante para os ouvintes de Jesus e também para a comunidade de Lucas. Jesus se apresenta como profeta escatológico que inaugura o evento do tempo final, a libertação definitiva. $\mathrm{O}$ aspecto humano, histórico da libertação é evidente nas categorias de pessoas mencionadas, ainda que não possa ser reduzida a uma libertação puramente humana, sociológica. Esta realidade pode ser vislumbrada também, no cântico de salvação, no grito de júbilo de Lc 7, 22-23, expressão da consciência da salvação presente: Ide contar a João o que estais vendo e ouvindo: os cegos recuperam a vista, os coxos andam, os leprosos são purificados, os surdos ouvem, os mortos ressuscitam e aos pobres é anunciado o Evangelho....

Depois de cegos, coxos, leprosos, surdos, mortos, no ápice encontramos a evangelização dos pobres. A resposta de Jesus em Lc 7 e Lc 4 sublinham "e aos pobres é anunciado o Evangelho", que só formalmente se encontra ao lado dos outros sinais; na realidade esta sintetiza todos. Temos uma escatologia cristologizada e então historicizada ${ }^{4}$. A boa nova aos pobres se conjuga em termos de libertação. Em Lc 4, duas vezes o termo aphesis (libertação/remissão). Em Levítico, 25,10, na versão dos LXX, com eniautos apheseôs, vem designado o ano jubilar, no qual os patrimônios são devolvidos e vinha dada a liberdade aos escravos. Jesus se apresenta como profeta escatológico que inaugura o ano jubilar, evento do tempo final, libertação definitiva. Esta libertação toca o ser humano na sua integralidade, na sua totalidade. A libertação trazida por Jesus não compreende somente os bens puramente espirituais e futuros, comporta também uma dimensão histórica. A atitude de Jesus, predita neste dito de Lucas na sinagoga de Nazaré, será a tônica de todo o ministério de Jesus, demonstrada em tantos outros momentos do seu ministério.

Nesta mesma linha, os milagres ou sinais realizados por Jesus evidenciam assim que iniciou o tempo da salvação messiânica, o reino de satanás é colocado em crise e se instaura o Reino de Deus. Eles manifestam a pessoa de Jesus mesmo, pois Nele ação e palavras não se separam. E este Reino é uma grande novidade que muda a fisionomia do velho mundo: o pecado com as suas conseqüências (doença, dor, sobretudo a morte) são verdadeiramente vencidos, porque a salvação de Deus está agindo no mundo. Esta salvação atinge o homem todo, não somente a sua alma, mas também o seu corpo, a

${ }^{4}$ H. Schurmann, Il vangelo di Luca. Parte prima, Brescia, Paideia, 1983, p. 657. 
sua concretude histórica assinalada pela doença e pelo sofrimento. E atinge de modo especial os fracos, os doentes, os marginalizados da sociedade (leprosos, endemoniados, etc. $)^{5}$. Os milagres não são tanto provas [extrínsecas] da vinda do Reino, mas um dos modos pelo qual o Reino mesmo se faz presente. «Os milagres, portanto, falam a mesma linguagem da sua proclamação verbal: o Reino de Deus está aqui» ${ }^{6}$.

\section{Jesus diante da impureza que excluía a pessoa humana}

Na sociedade em que Jesus viveu, determinados objetos, ações, pessoas, animais, eram tidos como capazes de contaminar o ser humano que se colocava em contato com eles, impedindo a comunhão com o a divindade, por isso, a necessidade de submeter-se a diversos ritos de purificação mediante a água (lavar-se, aspersão, imersão), ou mediante sacrifício. A esfera na qual Jesus mostra a própria liberdade é primariamente aquela do relacionamento com as pessoas [só indiretamente aquela dos objetos e dos animais].

Destas pessoas vêm documentadas seis categorias diversas: os leprosos (Lv 13,45-46); as mulheres com fluxo de sangue; os cadáveres; os pagãos; os publicanos e as prostitutas. Para cada um destes casos, os evangelhos mostram a inobservância de Jesus destas prescrições, que contaminam com a impureza somente no tocar.

Os leprosos: segundo a Lei mosaica, a lepra era uma impureza contagiosa, por isso o leproso era excluído da comunidade até a sua purificação. Diz o Levítico: O leproso portador desta enfermidade trará suas vestes rasgadas e seus cabelos desgrenhados; cobrirá o bigode e clamará: impuro! Impuro! Enquanto durar a sua enfermidade, ficará impuro e, estando impuro, morará à parte: sua habitação será fora do acampamento (Lv 13, 4546). Um Israelita observante da Lei não entraria em contato com um leproso por temor de contrair a impureza. A Lei proibia tocar numa pessoa impura

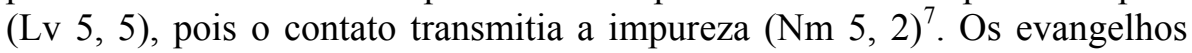
narram dois encontros de Jesus com leprosos, nos quais ele os toca (Mc 1,40-45; Lc 17,12-14).

Mulher que sofria fluxos de sangue: entrar em contato com uma mulher que sofria fluxos de sangue tornava impura a pessoa que entrasse em contato com ela (Lv 25, 25-27; Ez 36, 17). Esta situação colocava a mulher

\footnotetext{
${ }^{5}$ M. SerenthÀ, "Misteri di Cristo", in Dizionario Teologico Interdisciplinar. Supplemento, Marietti 1978,18.

${ }^{6}$ B. L. Blackburn, The Miracles of Jesus, 373; G. BARBaglio, Il regno di Dio e Gesù di Nazaret, p. 111.

${ }^{7}$ J. Mateos \& F. CAmacho, O Evangelho de Mateus, Edições Paulinas, São Paulo 1993, 89.
} 
num estado constante de impureza religiosa, impedindo-a de entrar no santuário, de participar das festas religiosas, por exemplo, da festa da Páscoa. A excluía mesmo da vida social ${ }^{8}$. Os Evangelhos neste caso narram o encontro de Jesus com a hemorroíssa (Mc 5,25-34 // Mt 9,20-22 // Lc 8, 43-48).

Os cadáveres: $\mathrm{O}$ contato com um cadáver tornava a pessoa impura. Os Evangelhos narram ao menos dois casos: a filha de Jairo (Mc 5,35-43 // Mt 9,18-19.23-25 // Lc 8,49-55); e o filho da viúva de Naim (Lc 7,11-15).

Os publicanos e pecadores: (Lv 19, 29; Dt 23, 18-19). O material nesta temática é abundante: refeição de Jesus com os pecadores (Mt 9,9-13 // Mc 2,13-17 // Lc 5,27-32) ${ }^{9}$. Jesus ao condividir a mesa dos pecadores, ele os associa indiretamente à mesa escatológica da graça, da qual ele mesmo é o portador. Os fariseus murmuravam: "Porque come o vosso mestre com os publicanos e pecadores?" (Mt 9, 11 // Mc 2, 16 // Lc 5, 30). O comportamento de Jesus aqui tem um colorido judaico - palestinense típico: a polêmica com os pecadores se refere indubitavelmente ao Jesus terreno. A posição de Jesus é daquele que se preocupa mais com o transgressor que com a transgressão, mais com o pecador que com o pecado: Não são os que têm saúde que precisam de médico, mas sim os doentes [...] Não vim para chamar os justos, mas os pecadores (Mt 9,12-13 // Mc 2,17 // Lc 5, 31-32). Este é o habitual comportamento de Jesus com relação a todos que são assinalados pela sociedade como marcados pela infâmia ritual ou moral. O pecador não é mais considerado como excluído do âmbito da salvação, mas convidado ao Reino de Deus mediante a oferta antecipada do perdão.

Os pagãos: (A.Z. 1,1; 4,9); há o encontro com a mulher siro-fenícia (Mc 7,24-30; Mt 15,21-28) e aquele com o centurião de Cafarnaum (Mt 8,513; Lc 7,1-10; Jo 4,46-53), etc. Outros casos lêem-se ainda em Mt 11,19; Lc 7,34 .

Jesus se manifesta como um homem livre, que vai contra a corrente e contra o sectarismo. Jesus se manifesta contra aquelas atitudes que humilham a pessoa humana e mortificam a sua dignidade (Lc 19,9 sobre Zaqueu: «também ele não é Filho de Abraão?»). A preferência pelos impuros e pecadores diz que Jesus é portador da misericórdia de Deus para eles. Jesus age em nome de Deus e por conta de Deus mesmo; ele encarna em si mesmo a misericórdia e o amor de Deus para aqueles que são necessitados. A redação

\footnotetext{
${ }^{8}$ R. PESCH, Il vangelo di Marco, I, 476.

${ }^{9}$ G. Rossé, Il vangelo di Lucas. Commento esegetico e teológico, Città Nuova Editrice, 1995, 186 comenta: Che Gesù abbia mangiato in casa di Levi, figlio di Alfeo, nome di certo non inventato, assieme ad altri dello stesso mestiere, è piu che probabile; che Gesù inoltre avesse l'abitudine di frequentare questi ambienti e che tale comportamento abbia suscitato il rimprovero dei benpensanti è storicamente certo.
} 
lucana das parábolas da misericórdia (Lc 15,4-32: a ovelha desgarrada, a dracma, o filho pródigo, todos os três perdidos e reencontrados) colocará em luz, próprio esta realidade. Jesus as conta para justificar-se diante dos fariseus e escribas, que murmuram escandalizados ao ver que ele «acolhe os pecadores e come com eles» $(15,1-2)$ : mas é próprio no seu comportamento que Deus mesmo se revela como aquele que vai ao encontro de quem é necessitado.

A tradição conservou dois outros casos de oposição de Jesus a duas prescrições referentes a coisas materiais. Um diz respeito ao corban [aquilo que é oferecido], segundo o qual qualquer coisa oferecida a Deus assumia aspecto de sacralidade e por isso, não podia ser usada profanamente. $\mathrm{O}$ preceito de Nm 30, 3 diz: Se um homem fizer um voto a Iahweh ou se obrigar por juramento a uma promessa formal, não violará a sua palavra: tudo aquilo que sair da sua boca, executará. Jesus trata de um caso muito concreto, aquele da omissão dos deveres filiais na assistência aos genitores, cumpridas em nome do corban (Mc 7,8-13 // Mt 15, 3-9). Jesus recorda que Moisés, como legislador, tinha dado no decálogo a obrigação de honrar pai e mãe. Como segunda disposição de Moisés vem citada a ameaça da pena de morte para quem desonrar pai e mãe (Ex 21, 17; Cf. Lv 20,9; Dt 27,6). De acordo com a tradição judaica, a honra devida aos pais incluía também o dever de cuidar do seu sustento. Evidentemente, Jesus não se opõe à Tôrah, mas se confronta com a halaká, interpretada por Jesus como tradição humana, em contraste com o preceito de Deus. O comportamento de Jesus deve ser tido no mínimo, como disturbador ${ }^{10}$.

As prescrições levíticas sobre a pureza no judaísmo apontavam uma série de coisas relacionadas com o externo que tornam impura a pessoa humana: objetos, alimentos, animais, situações, etc. Daí a necessidade de purificações expiatórias que restauravam este estado que se tinha perdido mediante o contato com o impuro. Jesus contrapõe a esta realidade. A sua posição se restringe a uma frase: Não há nada de fora do homem que entrando neste o possa contaminar, mas são as coisas que saem do homem que o contaminam (Mc 7,15// Mt 15,11). Jesus reconduz o discurso sobre a pureza para além das prescrições legais e o coloca no interno da pessoa humana e nas suas raízes éticas, como que dizendo que só o pecado pode contaminar.

Jesus observa, como normal, muitos costumes que não tem um fundamento bíblico. Um convite a não observância da lei não se encontra nunca na boca de Jesus. Não há dúvida, que Jesus se comporta com total liberdade

\footnotetext{
${ }^{10}$ R. Pesch, Il vangelo di Marco, I, 581-584; J. GNILKA, El Evangelio segun san Marcos, I, 328-330.
} 
diante da Torah e da halaká. Jesus reivindica uma autoridade que o coloca acima da lei. Ele sabe ser mensageiro de Deus e do seu designo escatológico, não da lei. Jesus convida Israel a acolher o Reino de Deus. Isto supõe da sua parte uma especial experiência de Deus e da concepção da sua realeza. A lei era destinada a ser superada mediante uma nova irrupção do senhorio de Deus. A consciência deste inaudito superamento (Mc 1,15): «o tempo se cumpriu... »; Mt 21,31: «Os publicanos e as prostitutas vos precederão no reino de Deus», caracteriza de maneira típica o ministério de Jesus.

\section{O Deus de Jesus Cristo, Deus do Amor e da vida}

O ministério de Jesus nos revela uma concepção nova de Deus, nos revela Deus como Senhor, mas porque é Senhor, pode servir. Este Deus só pode ser aquele que João define como Amor: Deus é amor (1Jo 4, 8. 16), aquele que é amor em si e porque o é em si, é amor também para nós ${ }^{11}$. Se Deus pode se manifestar na história de Jesus Cristo como amor que se autocomunica, é porque ele é em si mesmo este amor ${ }^{12}$. Aquele que sendo mistério de amor, é mistério de comunhão, de doação eterna na geração do Filho e na processão do Pneuma, e que na história manifesta este amor. Esta concepção de Deus nos revela que o ser humano deve ser um para o outro. Pessoa no mistério de Deus Amor é relação. Por pessoa se designa as relações subsistentes em Deus: O Pai, O Filho e o Espírito Santo. Para os padres Gregos e latinos, pessoa ou hypóstasis em Deus se diz então relações, ser voltado para o outro. Pessoa em Deus é diálogo. O símbolo de Toledo de 9 de novembro de 675 usa o conceito de pessoa igual à relação, como modo adequado de falar da Trindade. Por isso, pessoa em teologia trinitária foi definida como relacio subsistens (relação subsistente). São as relações que constituem o Pai, o Filho e o Espírito Santo como pessoas singulares e ao mesmo tempo une sua comum participação na dignidade de uma única natureza divina. Chama-se relação subsistente, porque esta existe e subsiste próprio com as relações. A sua realidade reside neste seu ser pessoa-relação e não substância. Deste modo, se pode atribuir plena realidade as três pessoas trinitárias sem diminuir a plenitude de sua comunhão e a única natureza divina. O Filho, por exemplo, não é uma substância ao lado daquela do Pai, mas é totalmente "ser do Pai" e "ser voltado para o Pai". Ele subsiste nesta relação

\footnotetext{
${ }^{11}$ JÜNGEL, Dio, mistero del mondo, Brescia, Queriniana, 1982, p. 427 diz: "Dio é amore [...] Dio è [...] l'evento irraggiante dell'amore stesso. [...] Dio há se stesso donandosi. Ma così, donandosi, si há. Così è. Il suo aversi è l'evento, è la storia di un donarsi. [...] Come questa storia egli è Dio, anzi questa storia dell'amore è Dio stesso".

${ }^{12}$ W. KASPER, Gesù il Cristo, Brescia, Queriniana, 1996, p. 256.
} 
com o Pai. Mesmo sendo um com o Pai na natureza, é, porém distinto do Pai enquanto é Filho e não Pai. Em Deus, o termo pessoa revela toda a sua originalidade: esta não é solidão, mas relação subsistente. A primeira pessoa não gera o Filho como se o ato de gerar se acrescentasse à pessoa pronta, na verdade ela é o ato de gerar, de entregar-se e de emanar. Ela é idêntica ao ato de se entregar. Ela não é o doador, mas o ato de doar. Ela só é pessoa com esse ato. Assim, aquele que pode ser todo - relação na história, é porque na Trindade eterna, é todo relação, todo dom. Assim, descobre-se a relação como um modo de ser original e equivalente do real ${ }^{13}$. O ser humano, criado a imagem de Deus amor, é o ser da relação por excelência. Ele é assim, criado para ser dom na história. A pessoa humana se realiza então, na sua capacidade de ser para o outro, de ser doação.

Toda a criação e a história da salvação será história deste serviço de amor gratuito e generoso de Deus ao ser humano. Um Deus-amor que se manifesta próximo do ser humano, convidando-o em Jesus Cristo e no dom do Espírito a uma comunhão profunda de vida com Ele. É preciso redescobrir esta imagem de Deus como Amor infinito, cuja onipotência é aquela do amor, não aquela do poder do mundo. Um Deus que se manifesta na humildade; humildade que se conjuga com o sofrimento do Amor.

A Igreja, comunidade dos discípulos e discípulas de Jesus Cristo deve ser a comunidade do amor e do serviço. Aquele que veio para servir e não para ser servido, curar, reconciliar, aquele que foi de modo excepcional o bom samaritano, vivenciou na história, aquilo que ele é na Trindade eterna, dom, relação. Jesus era o homem para os outros, assim deve ser a Igreja, ser a comunidade para os outros ${ }^{14}$.

\section{Conclusão}

Jesus foi comprometido com a vida na sua integralidade. Desde a proclamação na sinagoga de Nazaré até a sua atitude diante de todas aquelas pessoas que a sociedade judaica via como marcadas pela infâmia ritual e por isso, eram excluídas da vida social normal e também religiosa. Em Jesus de Nazaré a religião não é motivo de opressão do ser humano, mas de sua libertação. Jesus vai contra tudo aquilo que oprime a dignidade da pessoa humana. A salvação que ele trás atinge o ser humano na sua totalidade. A partir do

\footnotetext{
${ }^{13}$ J. RAtzinger, Introdução ao Cristianismo, São Paulo, Edições Loyola, 2005, p. 137; W. KASPER, Il Dio di Gesù Cristo, Brescia, Queriniana, 1994, 411 diz: "Le tre persone trinitarie sono pura relazionalità; sono relazioni in cui l'única essenza di Dio sussiste in tre modi diversi e inconfondibili. Esse sono relazioni sussistenti".

${ }^{14}$ R. CARdinal Cushing, The servant church, 6 .
} 
ministério de Jesus, a opção do cristianismo na fidelidade a Jesus, deverá ser pela vida na sua integralidade. Jesus vai contra tudo aquilo que oprime a dignidade da pessoa humana. A sua salvação atinge o ser humano integral. Num mundo desumano, frio, tecnológico, o segmento de Jesus deve ser humanizante e deve comprometer com a humanização. Em Jesus, Deus se revela como aquele que é pelo humano. Um Deus que manifesta na humildade, humildade que se conjuga com o amor.

Paulo Cezar Costa

Reitor do Seminário Paulo VI

Sacerdote da Diocese de Valença

Diretor e Professor do Departamento de Teologia da PUC-Rio Doutor em Teologia pela Pontifícia Universidade Gregoriana da Roma 